\title{
Evaluation of the fretting corrosion mechanisms on the head-cone interface of hip prostheses
}

\author{
I. Caminha ${ }^{1}$, C. R. M. Roesler ${ }^{2}$, H. Keide ${ }^{1}$, C. Barbosa ${ }^{1}$, I. Abud ${ }^{1}$ \\ \& J. L. Nascimento ${ }^{1}$ \\ ${ }^{1}$ Laboratory of Characterization of Mechanical and Microstructural \\ Properties, National Institute of Technology (INT), Rio de Janeiro (RJ), \\ Brazil \\ ${ }^{2}$ Laboratory of Biomechanical Engineering, University Hospital, \\ Federal University of Santa Catarina (UFSC), Brazil
}

\begin{abstract}
Fretting-corrosion is one of the main concerns in the application of hip prosthesis. This type of information is very important in the stage of orthopedic implants design, with the purpose of minimizing the amount of tissue exposed to corrosion products which are released during the permanence of the prosthesis in the patient. The residual corrosion products of stainless steels are associated to the occurrence of several adverse reactions in the human body. The knowledge about these corrosion products is extremely important in the phase of the project of hip prostheses, aiming at the minimization of the amount of exposure of the organic tissues to corrosion products released during the permanence of the prosthesis inside the patient.

In the present work the mechanical stability and fretting corrosion resistance of modular hip prosthesis, which was fabricated with ASTM F 138 austenitic stainless steel, were evaluated according to the criteria of ASTM F 1875 standard, method I, which prescribes long term test, with the purpose of determining the amount of damage through the quantification of the corrosion products and debris which resulted from the fretting corrosion conditions. The mechanical tests were performed in a servohydraulic mechanical testing machine and the modular interfaces were exposed to an electrolytic $0.9 \% \mathrm{NaCl}$ in distilled water solution and subjected to a minimum load of $230 \mathrm{~N}$ and a maximum load
\end{abstract}


of $2.3 \mathrm{kN}$, frequency of $5 \mathrm{~Hz}$ for 10 million cycles, according to ASTM F 1875 standard, thus simulating real conditions of use. Load ratio $(\mathrm{R}=10)$ was determined in ASTM F1440 standard. A significant amount of fretting-corrosion products were observed: $0.22 \mathrm{~g}$ resulted from five specimens after $10^{7}$ million cycles, and the diffraction $\mathrm{X}$-Rays tests showed the presence of the crystalline phases $\mathrm{Fe}_{2} \mathrm{O}_{3}, \mathrm{Fe}_{3} \mathrm{O}_{4}$ and $\mathrm{Cr}_{2} \mathrm{O}_{6}$.

It can be concluded that the mass loss in the head-cone connection allowed the entrance of the physiological saline solution in the inner region of the head, increasing the predicted micro movement in the head-cone interface, resulting in an accelerated process of fretting-corrosion, and consequently the liberation of debris and corrosion products that could lead to adverse biological reactions.

Keywords: fretting corrosion, hip prosthesis, modular components, mechanical properties.

\section{Introduction}

The increasing life expectancy in the last decades and trauma risk due to the more frequent exposure of individuals to different types of accidents and current insecure life conditions has led to an increased search for orthopedic implants with high performance, capable of resisting to even more severe loads for longer times. For this reason, metallic materials, which were developed for applications in orthopedic implants, must present some specific properties, such as biocompatibility, strength and resistance to degradation (by wear or corrosion).

In spite of the increasing use of titanium and its alloys for this application in the last decades, in Brazil ASTM F138 austenitic stainless steel $[1,2]$ is still very used in the fabrication of modular components for total hip arthroplasty due to its lower cost, together with good mechanical properties and satisfactory corrosion resistance, since the main customer is Health Ministry, which supplies the demands of public hospitals in Brazil.

The use of modular components in the total hip arthroplasty presents several advantages, such as a great variety of stem geometry, which allows a better choice of modular component for the surgeon, according to the patient disease, mainly in the case of revision surgeries, thus minimizing the risk of inadequate procedures.

However, the modular interfaces are subjected to micro movements, which can result in fretting and corrosion, leading to the release of debris, which can cause adverse reactions and accelerated wear in the articulation interface. "Fretting" can be defined as a wear phenomenon which occurs when two solids in contact are subjected to tangential oscillatory movement with small displacement amplitude. It can be described more accurately as a movement whose amplitude is smaller than the contact extent. The presence of a corrosive environment contributes to accelerate the wear process and this condition is defined as "fretting-corrosion". The occurrence of corrosion results in degradation processes which reduce the structural integrity of the implant and release products whose reaction can be harmful in contact with organic tissue. 
When the prostheses are fabricated with ASTM F138 stainless steel, the generation of a passive barrier in the surface (passive layer) is the main obstacle to corrosion process. This film, which is composed by metallic oxides, formed spontaneously on the metal surface, and whose thickness can be increased with surface treatments, avoids the migration of metallic ions from the metal to the solution and the migration of anions from the solution to the metal through the metal-solution interface (physiological environment). For being effective barriers these films must be compact and cover completely the metallic surface, they must have an atomic structure which limits the migration of metallic ions and/or electrons through the metallic oxide/solution interface, and they must be capable of remain on the surface of these alloys even when subjected to mechanical and abrasive stresses in the clinical use of prostheses.

The most frequently mentioned mechanisms of failure in these components are aseptic loosening, periprosthetic osteolysis and metallosis and are directly related to the debris released by the prosthesis components, mainly the non cemented prostheses [3].

According to the literature [4], the residual products of corrosion in stainless steel based implants are associated to tissue necrosis, inflammation, allergenic reactions and even cancer.

The aim of the present work is an evaluation of fretting corrosion in modular prostheses fabricated with ASTM F 138 stainless steel, in order to minimize the adverse reactions during the permanence of the prosthesis in the patient.

\section{Material and methodology}

In this work five modular hip prostheses, composed by heads and stems, five stems and five heads, fabricated with ASTM F 138 from the same batch, were analyzed. A SZX16 model Olympus stereomicroscope was used for comparing the surfaces of the modular components before and after fretting corrosion test. In Fig. 1 an as received representative sample of the batch can be observed.

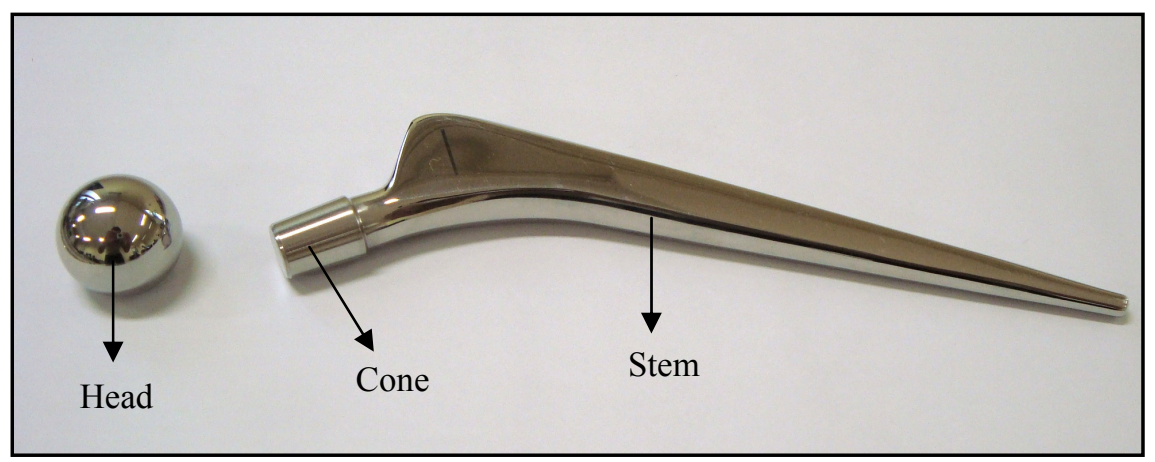

Figure 1: Head and stem of the hip prosthesis fabricated with ASTM F 138 stainless steel. 
The fretting corrosion tests on the cone-head interface were performed according to method I of ASTM F 1875 standard, which prescribes a $0.9 \% \mathrm{NaCl}$ physiological saline solution, thus simulating in vivo conditions, since that when implanted in patients these components are in contact with body fluids. With the purpose of analyzing both fatigue resistance of hip stems and mechanical stability of modular components the experimental procedures described in ASTM F 1440 [5] and ISO 7206-4 [6] were also adopted.

These tests were performed in two universal machines for mechanical testing (Instron model 8872) with a $25 \mathrm{kN}$ load cell with the following characteristics, described in ASTM F 1875 standard [7]:

- Maximum load: $3.3 \mathrm{kN}$;

- Frequency: $5 \mathrm{~Hz}$;

- Test finish after 10 million cycles;

- Error of applied load lower than $1 \%$ of the maximum load;

- Control function of cyclic load (sinusoidal);

- Monitoring of vertical displacement of the prosthesis head and registering of cycles counting;

- Computerized operation;

- Equipment for recirculation and heating of solution test with temperature control within $37^{\circ} \mathrm{C} \pm 1^{\circ} \mathrm{C}$.

Before starting the test each modular component composed by head and stem was prepared according to the following procedure:

- Assembling the modular component and checking the fittings;

- Placing the modular component in a device which allows alignment of angles referred in the standard, in concern to the load direction;

- Drying the mounting;

- Introducing the environment chamber together with the metallic cup with the mounted prosthesis;

- Adding the saline solution $(0.9 \% \mathrm{NaCl}$ in distilled water $)$ to the environment chamber;

- Starting the pump for recirculation and heating the test solution;

- Fitting the complete assembly in the test machine (Fig. 2).

The machine was programmed for the application of the load in the center of the prosthesis head, with minimum $0.3 \mathrm{kN}$ and maximum $3.3 \mathrm{kN}$ loads, with sinusoidal $5 \mathrm{~Hz}$ frequency according to the conditions specified in ASTM F1875 standard. Maximum load requirements are specified in ISO 7206-4-2010 standard.

A limiting condition was imposed for automatically stop ping the machine: a vertical displacement of $5 \mathrm{~mm}$. If this value is not reached the test is finished after completing 10 million cycles of loading and unloading. The parameters of sample placement follow the requirements of ASTM F1440 standard. 


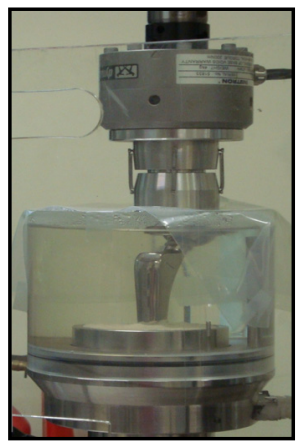

Figure 2: Complete assembly before starting test in INSTRON 8872 machine.

X-ray diffraction analysis was carried out in the following conditions: anode material: $\mathrm{Cu} \mathrm{K \alpha}$, angle between 10 and $100^{\circ}$, step size $0.05^{\circ}$, scan step time: $1 \mathrm{~s}$, receiving slit size: $0.03 \mathrm{~mm}$, current: $40 \mathrm{~mA}$, voltage: $40 \mathrm{kV}$.

\section{Results and discussion}

The images of the modular surfaces (head and cone), which were obtained by optical microscopy, did not present surface defects such as cracks other types of flaws, introduced by the fabrication process, which could influence the results of this test. In Figs. 3 and 4 the aspect of the surface of the modular components (head and cone) of a hip prosthesis, before and after testing, are presented. The other prostheses have similar aspects. A significant corrosive attack inside the head and in the cone can be observed after 1 million cycles with increasing rates along the test, releasing corrosion products which resulted in mass loss in the head-cone connection. The mass loss, which was observed in the test solution, allowed the introduction of saline solution inside the head, increasing the predicted micro movements, leading to an accelerated wear (friction), with tearing of debris, according to Fig. 6. No type cracks and mechanical failure could be observed in the five hip prostheses, which were analyzed, thus meaning that the mechanical stability of the modular component was preserved along the test.
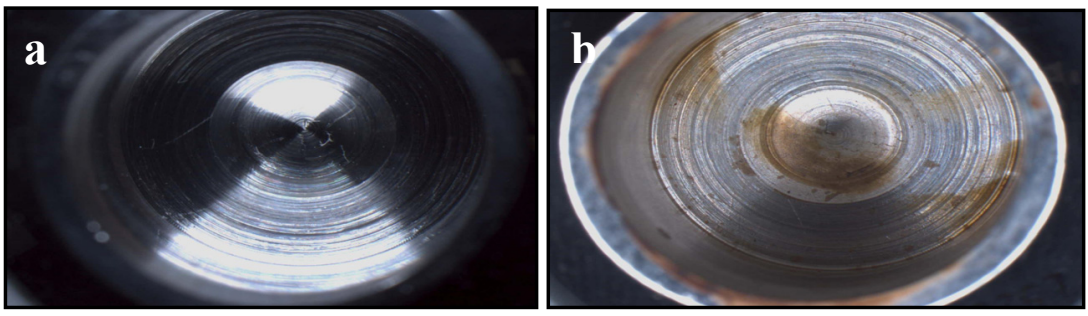

Figure 3: Detailed view inside the heads: (a) before and (b) after the test. Magnification: 10X. 
82 Materials Characterisation V
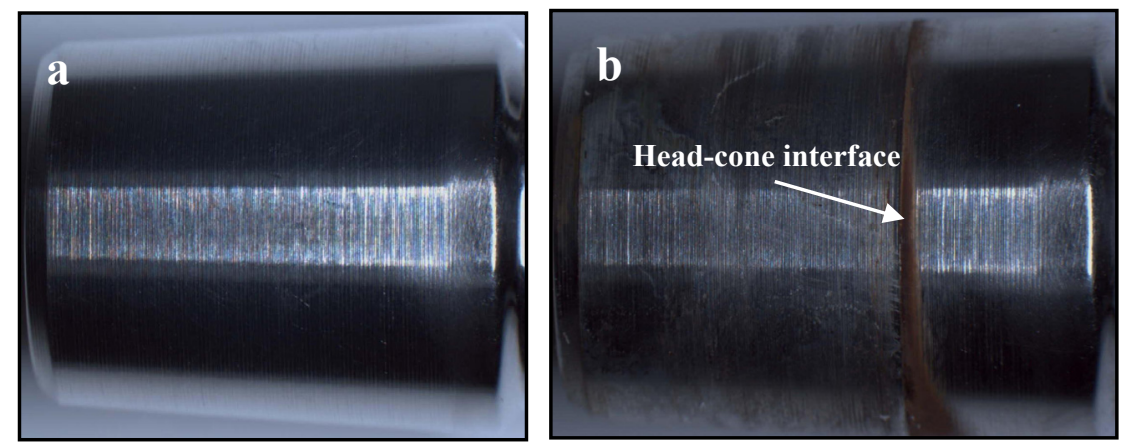

Figure 4: Detailed view of the cone region: (a) before (b) after. Magnification: 10X.

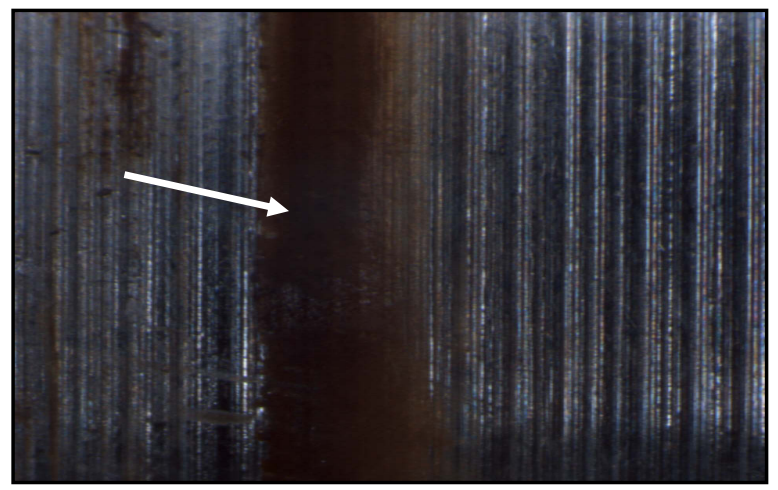

Figure 5: Detailed view of the head-cone interface connection shown in Fig. 4-b. Magnification: 60X.

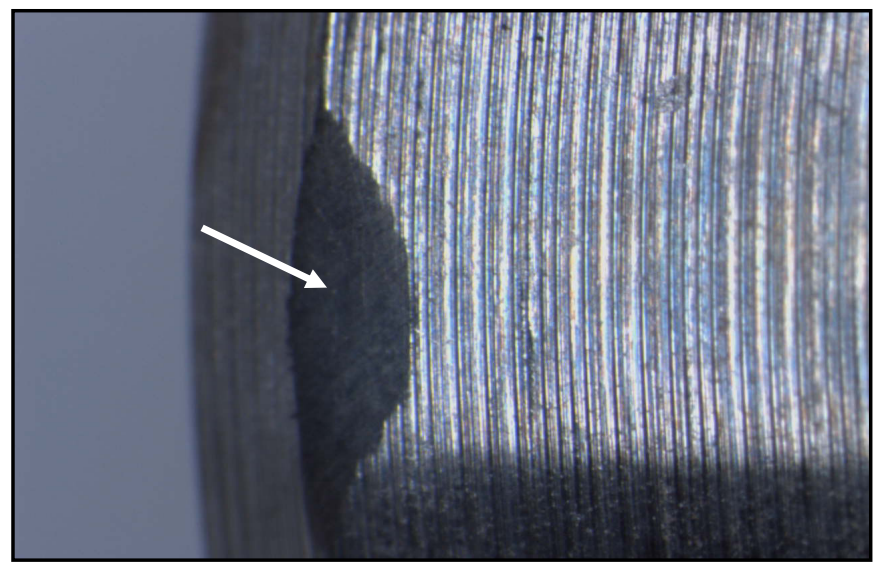

Figure 6: Detailed view of tearing which was observed on the cone. Magnification: 60X. 
In Figs. 7 and 8 the corrosion products and particulate residues (debris), resulting from the fretting corrosion test can be observed in the bottom of the environment chamber (indicated by an arrow in fig. 8). These ones are consequence of the damages caused by fretting and corrosion fretting in the head-cone interface of the primary hip prosthesis. These images represent the five hip prostheses subjected to this analysis.

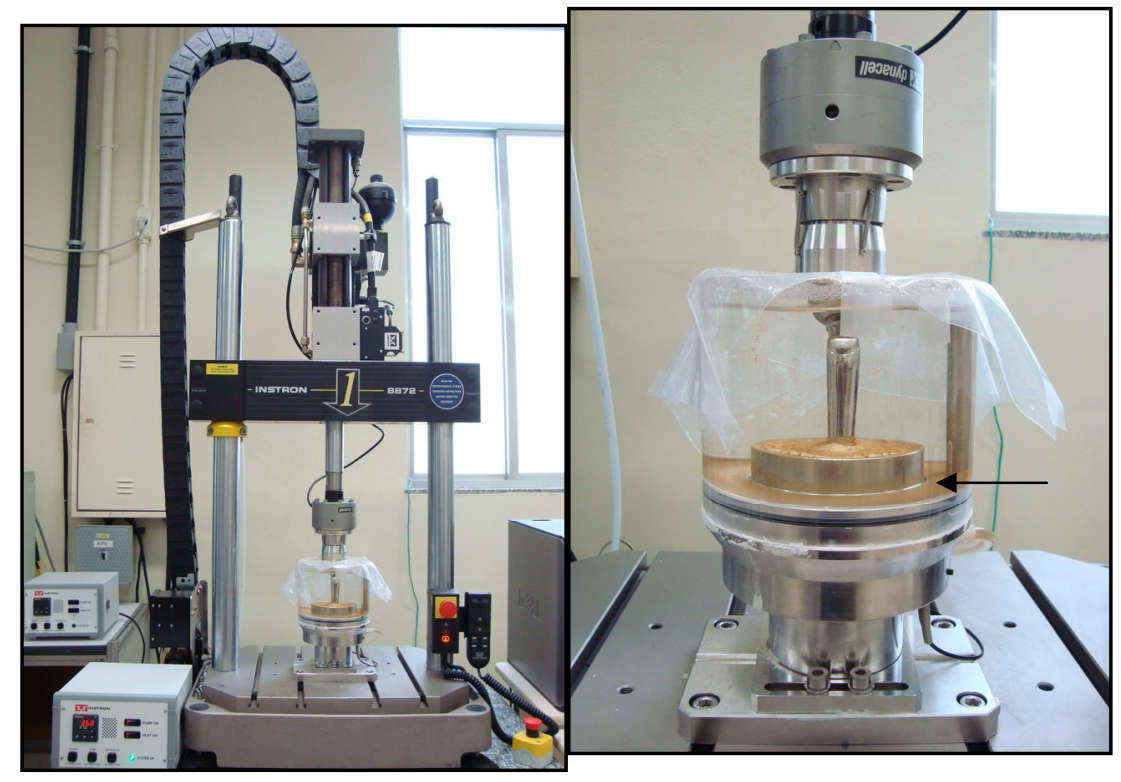

Figure 7: Test assembly after $10^{6}$ cycles. $\quad$ Figure 8: Detail.

Until 1 million cycles neither corrosion products nor particulate debris could be observed, but after this period the degradation of the modular component was increasing and localized on the head-cone, as can be seen in detail in Fig. 5.

After 10 million cycles the corrosion products and particulate debris were quantified, resulting in an average value of $0.22 \mathrm{~g}$. In the literature there is only one citation of fretting-corrosion products quantification, but in their experiment the cycle number was varied, thus hindering any type of comparison with the results presented in this work.

For better comprehension of fretting corrosion mechanisms in hip modular components the variation of load and number of cycles is necessary. The characterization of the corrosion products and particulate residues by X-ray analysis is also very important, in order to identify the phases and type of metallic particles which were released, with the aim of minimizing the incidence of aseptic loosening, periprosthetic osteolysis and metallosis in the surgeries of total hip arthroplasty. In the present work a complete characterization of the fretting corrosion products was not concluded, but it can be observed that they presented a predominantly ellipsoidal shape with size distribution approximately uniform, whose larger diameter was around $500 \mu \mathrm{m}$. 
Anyway, the X-ray diffraction analysis performed in the corrosion products showed the presence of the following crystalline phases: $\mathrm{Fe}_{2} \mathrm{O}_{3}, \mathrm{Fe}_{3} \mathrm{O}_{4}$ and incipient $\mathrm{Cr}_{3} \mathrm{O}_{8}$, compatible with the ASTM F138 stainless steel.

\section{Conclusion}

The evaluation of fretting corrosion on the head-cone connection interfaces of five modular hip prosthesis fabricated with stainless steel led to the following results:

- A significant grade of localized corrosion in the inner region of the head and in the head-cone interface was observed, originated from the fretting corrosion and fretting during 10 million cycles, resulting in particulate debris and corrosion products.

- In order to achieve a better comprehension of the fretting corrosion mechanisms, more tests are necessary, including changes in the applied load and number of cycles.

- At first glance, fretting corrosion does not affect the mechanical stability of the modular components, at least until $10^{7}$ cycles.

\section{References}

[1] Cavalcanti, E.H. de S., Souza, S.M.C. de, Ferreira, C. de A., Campos, M.M., Abud, I. de C. and Palmeira, L., (2002), "Avaliação da Resistência à Corrosão de Prótese Total de Quadril de Aço Inoxidável Austenítico Removida de Paciente", $22^{\circ}$ CONBRASCORR - Congresso Brasileiro de Corrosão, Salvador - Bahia.

[2] Giordani, E.J., Ferreira, I. and Balancin, O., (2007), "Propriedades mecânicas e de corrosão de dois aços inoxidáveis austeníticos utilizados na fabricação de implantes ortopédicos", REM: R. Esc. Minas, Ouro Preto, 60(1): 55-62.

[3] Crestani, M.V., Boschim, L.C. and Schwartsmann, C.R., (2004), "Metalose Simulando Tumor Abdominal", Revista Brasileira de Ortopedia, Nov/Dez. 2004.

[4] Merritt, K.; Brown, S.A.; (1985), "Biological Effects of Corrosion Products from Metals", Corrosion and Degradation of Implant Materials: Second Symposium, ASTM STP 859, A.C. Fraker and C.D. Griffin, Eds., American Society for Testing and Materials, Philadelphia, 1985, pp. 195-207.

[5] ASTM F 1440 - 92 (Reapproved 2008), Standard Practice for Cyclic Fatigue Testing of Metallic Stemmed Hip Arthroplasty Femoral Components Without Torsion.

[6] ISO 7206-4-2010 - Implants for surgery - Partial and total hip joint prostheses -- Part 4: Determination of endurance properties and performance of stemmed femoral components.

[7] ASTM F 1875 - 98 (Reapproved 2004), Standard Practice for Fretting Corrosion Testing of Modular Implant Interfaces: Hip Femoral Head-Bore and Cone Taper Interface. 